\title{
Autoantibodies in Type-2 Diabetes having Neurovascular Complications Bind to the Second Extracellular Loop of the 5-Hydroxytryptamine 2A Receptor
}

\author{
Mark B. Zimering*
}

Endocrinology, Veterans Affairs New Jersey Healthcare System, East Orange, NJ and Rutgers-Robert Wood Johnson Medical School, New Brunswick NJ, USA

*Corresponding author: Mark B. Zimering, Endocrinology, Veterans Affairs New Jersey Healthcare System, East Orange, NJ and Rutgers-Robert Wood Johnson Medical School, New Brunswick NJ, Medical Service (111); 151 Knollcroft Rd. Lyons, NJ 07939, USA; Phone: 908647 0180 x4426; Fax: 908 604-5249; Email: mark.zimering@va.gov

Received: June 13, 2019; Accepted: June 27, 2019; Published: August 14, 2019;

\section{Introduction}

Diabetes is associated with a substantially increased risk of certain neurovascular and neurodegenerative complications, e.g. stroke, dementia, Parkinson's disease, major depressive disorder [1], through complex and poorly-defined mechanisms. We previously reported the occurrence of activating 5-HT2A receptor IgG autoantibodies in plasma or serum from older adult diabetes suffering with major depressive disorder [2], Parkinson's disease or dementia [3]. Acute neurite retraction and accelerated mouse neuroblastoma N2a cell death induced by the autoantibodies in cell culture was partially or completely prevented by co-incubation (of IgG autoantibodies) with selective antagonists of the 5-HT2A receptor [2,3].

The second extracellular loop region of several different G-protein coupled receptors lies adjacent to the receptors' orthosteric binding pocket [4]. In subsets of human dilated cardiomyopathy [5] or in eclampsia [6], spontaneously- occurring auto antibodies which targeted the second extracellular loop region of the beta-1adrenergic or the angiotensin II, type 1 receptor, respectively, caused G-protein coupled receptor activation. In the present study, we tested a hypothesis that IgG autoantibodies in older adult diabetes having angiopathic and/or neurodegenerative complications cause 5-HT2A receptor activation via binding to the second extracellular loop region of the 5-HT2A receptor.

The 5-HT2A receptor is highly expressed in specific brain regions underlying cognition, perception and mood regulation [7]. It is also expressed on vascular smooth muscle cells where it plays a role in the regulation of arterial vascular tone [8]. Autoantibodies targeting 5-HT2A receptors in the central nervous system and the peripheral vasculature could serve as a biomarker for complications associated with refractory hypertension (e.g. stroke, chronic kidney disease) and/or neurodegeneration (dementia, Parkinson's disease, retinal degeneration).

\section{Participants and Methods}

\section{Participants}

Men and women enrolled in the Diabetes or Endocrinology clinics at the Veterans Affairs New Jersey Healthcare System (VANJHCS),
East Orange and Lyons NJ signed an informed consent for VANJHCS Institutional Review Board-approved study participation prior to blood drawing.

\section{Patient subgroups}

Patient 1: A 57-year-old man with morbid obesity, type 2 diabetes, stage 3 Chronic Kidney Disease (CKD) and refractory hypertension who suffered a branch retinal vein occlusion and Transient Ischemic Attack (TIA). He underwent renal biopsy which revealed hypertensive glomerulosclerosis (Fig 1).

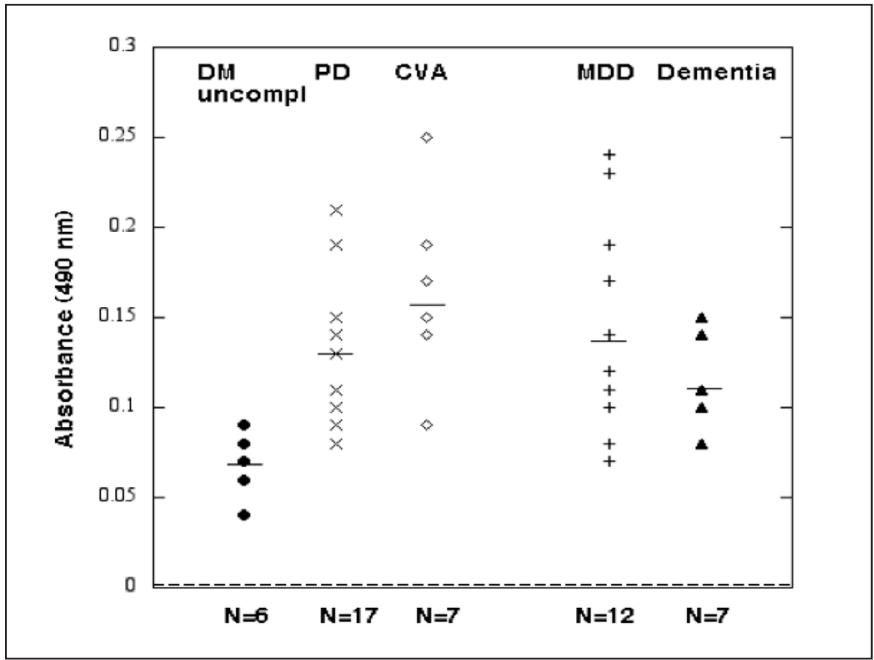

Figure 1. Enzyme linked immunosorbent assay using the synthetic peptide Q..N-18 as the solid-phase antigen. Results are arbitrary absorbance units (OD) in a one-fortieth dilution of the protein-A eluate fraction of plasma or serum from patients with uncomplicated type 2 diabetes $(\mathrm{N}=6)$, Parkinsons disease ( $\mathrm{PD})(\mathrm{N}=17)$, cerebrovascular accident (CVA) $(\mathrm{N}=7)$, major depressive disorder (MDD) $(\mathrm{N}=12)$ or dementia $(\mathrm{N}=7)$. Dashed line indicates background absorbance level of 0.04 absorbance units (dotted line).

Patient 2: A 72 -year-old man with twenty-year history of type 2 diabetes, discoid lupus erythematosus, and adult onset retinitis pigmentosa who had also suffered with a central retinal artery occlusion.

Patient 3: An 81 year-old-man who suffered with autoimmune thyroid disease and juvenile-onset retinitis pigmentosa (Stargardt disease). 
Mark B. Zimering (2019) Autoantibodies in Type-2 Diabetes having Neurovascular Complications Bind to the Second Extracellular Loop of the 5-Hydroxytryptamine 2A Receptor

He has a ten-year history of type 2 diabetes without microvascular complications. Family history is positive for Stargardt disease in one brother.

\section{Blood drawing}

Blood was drawn in the morning in fasted participants.

\section{Protein-A Affinity Chromatography}

Protein An affinity chromatography was carried out as previously reported [2].

\section{Synthetic peptide synthesis}

A synthetic peptide having the amino acid sequence QDDSKVFKEGSCLLADDN, hereafter referred to as Q..N-18 or peptide 1, was synthesized at Lifetein Inc.(Hillsborough, NJ) and had $\geq 92 \%$ purity. Q...N-18 had identical amino acid sequence to the region of the human 5-HT2A receptor comprising the second extracellular loop (ECL2) (Uniprot KB- P28223 [216 - 233] 5HT2A_ Human). Three shorter overlapping peptides having the following amino acid sequences: QDDSKVF (peptide 3), VFKEGSC (peptide 4), SCLLADDN (peptide 2) were synthesized at Lifetein, Inc. and had purities $\geq 96 \%$. The latter three peptides were used in epitope analysis of the Q..N-18 (ECL2) region targeted for binding in subsets of human neurovascular pathologies' autoantibodies.

\section{Enzyme Linked Immunosorbent Assay (ELISA)}

Ninety-six well plates were coated with the Q..N-18 peptide in PBS at a concentration of 65 micrograms $/ \mathrm{mL}$ for two hours at 25 degrees C. The plates were washed three times with $0.1 \%$ Triton X-100 in PBS (PBS/Triton). Next the plate was blocked with 3\% BSA in PBS for 1 hour at room temperature. Following 3 washes with PBS/Triton, $0.5-10 \mu \mathrm{g} / \mathrm{mL}$ concentrations of the patient IgG antibody (obtained by protein an affinity chromatography of plasma or serum) or a control sample was added to wells in duplicate and incubated for 1 hour at room temperature. The plate was washed $3 \times$ in PBS/Triton. Next HRP-conjugated goat anti human IgG (Sigma, St. Louis, MO) was added to each well at a 1: 3000 final dilution. After $1 \mathrm{~h}$ incubation, the plate was washed $3 \times$ in PBS/Triton. Next $150 \mu \mathrm{L}$ of a substrate solution containing $0.4 \mathrm{mg} / \mathrm{mL}$ ortho-phenylenediamine (Sigma, St. Louis, $\mathrm{MO}$ ) and $\mathrm{H}_{2} \mathrm{O}_{2}$ was added to each well and the reaction was monitored for color development. After 5 minutes, the reaction was stopped by the addition of $50 \mu \mathrm{L} 8 \mathrm{M} \mathrm{H}_{2} \mathrm{SO}_{4}$ and the optical density was read at $490 \mathrm{~nm}$ in a microtiter plate reader (Dynatech Inc). Results are expressed as basal $\mathrm{OD}_{490}$ compared to wells to which $\mathrm{PBS}$ alone was added.

\section{Mouse neuroblastoma N2 cells}

N2A cells were generously provided by Dr. Smith Varia and Dr. Janet Alder (Department of Neurosciences, Rutgers-Robert Wood Johnson Medical School). The cells were cultured in DMEM with 10\% fetal calf serum.

\section{N2A Acute Neurite Retraction assay}

Acute neurite retraction assay was performed as previously reported [2]

\section{$\mathrm{N} 2$ cell survival assay}

Cell survival assays were carried out as previously reported [2]

\section{Chemicals}

All chemicals (with the exception of synthetic peptides) were from Sigma Chem. Co, Inc.

\section{Protein determinations}

Protein assays were carried out as previously reported [2]

\section{Results}

\section{Baseline clinical characteristics in the study patients}

The baseline clinical characteristics are shown in Table 1. The study cohort included 49 older adults with type 2 diabetes mellitus (T2DM) and 7 older adults without diabetes. The patients without diabetes were slightly younger on average, but did not differ significantly from the diabetic patients in their mean body mass index 31.0 vs 34.9 $\mathrm{kg} / \mathrm{m}^{2}$ (Table 2).

Table 1. Baseline clinical characteristics in the 56 study patients

\begin{tabular}{|l|c|c|}
\hline \multicolumn{1}{|c|}{ Risk factor } & Mean (SD) & N \\
\hline Age (years) & $68.3(9.0)$ & 56 \\
\hline Non-diabetes * Type 2 Diabetes 49 & $61.8(10.8)$ & 7 \\
\hline Body mass index $\left(\mathrm{kg} / \mathrm{m}^{2}\right)$ & $34.9(6.8) 49$ & 49 \\
\hline Glycosylated hemoglobin(\%) & $8.0(1.6)$ & 49 \\
\hline Duration of diabetes (years) & $15.4(8.2)$ & 49 \\
\hline
\end{tabular}

*Major depressive disorder $(\mathrm{n}=2)$, Parkinsons'disease $(\mathrm{n}=3)$, Schizophrenia $(\mathrm{n}=1)$, Graves ophthalmopathy $(\mathrm{n}=1)$

Table 2. Comparison of age and body mass index in diabetic and non-diabetic patients.

\begin{tabular}{|l|l|l|}
\hline \multicolumn{1}{|c|}{ Diabetes $(\mathbf{n = 4 9 )}$} & \multicolumn{1}{|c|}{$\begin{array}{c}\text { No Diabetes } \\
(\mathbf{n}=\mathbf{7})\end{array}$} & \multicolumn{1}{|c|}{$\boldsymbol{P}$-value } \\
\hline Age (years) $69.0(7.2)$ & $61.8(10.8)$ & 0.04 \\
\hline Body mass index $\left(\mathrm{kg} / \mathrm{m}^{2}\right) 34.9(6.8)$ & $31.0(3.0)$ & 0.26 \\
\hline
\end{tabular}

Mean binding to a linear synthetic 5-HT2A receptor peptide did not differ significantly in autoantibodies from Parkinson's disease or major depressive disorder patients with or without type 2 diabetes (Table 3). These data suggest that the 'susceptible' population harboring increased 5-HT2A receptor peptide autoantibodies is likely to include older persons with and without type 2 diabetes mellitus.

Table 3. Mean 5-HT2A receptor peptide binding in diabetic vs nondiabetic patients having Parkinson's disease or major depressive disorder.

\begin{tabular}{|l|l|l|l|}
\hline Neurodegeneration & Diabetes & No Diabetes & $P$-value \\
\hline Parkinson's disease & $0.13(.04)[14]$ & $0.13(.05)[3]$ & 0.85 \\
\hline Major depression & $0.16(.06)[10]$ & $0.12(.04)[2]$ & 0.32 \\
\hline
\end{tabular}

Results are mean absorbance units $\mathrm{AU}+/$ (SD); [ ] number of patients 


\section{Increased 5-HT2AR synthetic peptide binding in protein-A eluates from subsets of diabetic angiopathy and/or neurovascular complications}

A one-fortieth dilution of the protein-A eluate of plasma (2-8 $\mu \mathrm{g} / \mathrm{mL} \mathrm{IgG}$ ) was tested for binding to the linear synthetic peptide Q...N-18 having an amino acid sequence identical to that of the second extracellular loop of human 5-HT2A receptor. Mean binding level was significantly increased $(\mathrm{P}<0.01)$ in subsets of diabetes having Parkinson's disease $(\mathrm{n}=17)$, dementia $(\mathrm{n}=7)$, stroke or TIA $\mathrm{n}=7$ ), or major depressive disorder $(\mathrm{n}=12)$ compared to the mean level in age-matched older adult type $2 \mathrm{DM}$ without significant angiopathy (i.e. retinopathy or nephropathy) ( $\mathrm{n}=6$; Fig 1). It was also significantly increased in diabetes patients with a coexisting systemic autoimmunity condition (i.e. discoid lupus erythematosus $(\mathrm{n}=1)$, ankylosing spondylitis $(\mathrm{n}=1)$, Graves orbitopathy $(\mathrm{n}=2)$, rheumatoid arthritis $(\mathrm{n}=1)$ ) (Table 4). Mean binding in the protein-A eluate fraction of T2DM plasma (IgG) was significantly increased in patients having significant retinopathy $v s$. no retinopathy, or diabetic nephropathy vs. no nephropathy (Table 5). There was no significant difference in plasma IgG autoantibody binding level in T2DM patients with or without atrial fibrillation, T2DM with or without obstructive sleep apnea or T2DM with or without co-morbid cancer (Table 5). Taken together, these data suggest associations among diabetic angiopathy, neurodegenerative disorders and certain systemic autoimmune diseases with increased level of IgG autoantibodies that binds to 5-HT2A receptor, second extracellular loop region, and linear synthetic peptide.

Table 4. Mean 5-HT2A receptor peptide binding in type 2 diabetes without angiopathy vs diabetes with a neurodegenerative disorders or a co-morbid systemic autoimmune condition $^{\wedge}$.

\begin{tabular}{|l|l|lc|}
\hline \multicolumn{1}{|c|}{ Mean receptor peptide binding } & \multicolumn{1}{c|}{$\mathbf{N}$} & \multicolumn{2}{c|}{$\boldsymbol{P}_{\text {-value* }}{ }^{*}$} \\
\hline Diabetes without angiopathy^ & $0.068(.01)$ & 6 & ----- \\
\hline Diabetes with dementia & $0.11(.02)$ & 7 & $<0.01$ \\
\hline Diabetes with PD** & $0.13(.04)$ & 17 & $<0.01$ \\
\hline Diabetes with MDD*** & $0.14(.05)$ & 12 & 0.02 \\
\hline Diabetes with CVA or TIA & $0.16(.04)$ & 7 & $<0.01$ \\
\hline Diabetes with Autoimmunity & $0.18(.05)$ & 5 & $<0.01$ \\
\hline
\end{tabular}

Results are mean $\mathrm{AU}+/-\mathrm{SD} ; \wedge^{\wedge}$ - without any neurodegenerative disorder; $\wedge^{\wedge}-\mathrm{N}=1$ each having discoid lupus erythematosus, ankylosing spondylitis, Graves disease, celiac disease, rheumatoid arthritis; *t-test compared to group having diabetes without angiopathy. PDParkinson's disease, MDD-major depressive disorder, CVA-cerebrovascular accident, TIA-transient ischemic attack. $* *$ includes 3 patients without diabetes; $* * *$ includes 2 patients without diabetes

Lack of association between IgG plasma autoantibody binding to 5-HT2A receptor peptide and patient age or diabetes duration

There was no significant association between mean $\operatorname{IgG}$ autoantibody binding to the 5-HT2A receptor peptide and baseline patient age, body mass index, glycosylated hemoglobin, or duration of diabetes (data not shown in Tables).
Table 5. Association between5-HT2AR, ECL2 receptor peptide binding and baseline diabetic micro-vascular or other complications.

\begin{tabular}{|l|c|c|c|}
\hline & Present (N) & Absent (N) & $\begin{array}{c}\text { Absent } \\
(\mathbf{N})\end{array}$ \\
\hline Diabetic retinopathy & $0.15+0.05(16)$ & $0.10+0.04(27)$ & 0.002 \\
\hline Diabetic nephropathy & $0.13+0.04(21)$ & $0.1+0.04(21)$ & 0.006 \\
\hline Diabetic painful neuropathy & $0.13+0.05(21)$ & $0.1+0.05(19)$ & 0.12 \\
\hline Atrial fibrillation & $0.13+0.05(19)$ & $0.13+0.05(34)$ & 0.87 \\
\hline Obstructive sleep apnea & $0.12+0.05(20)$ & $0.12+0.05(28)$ & 1.0 \\
\hline Cancer & $0.14+0.05(13)$ & $0.12+0.05(36)$ & 0.13 \\
\hline
\end{tabular}

Results are mean $\mathrm{AU}+/-\mathrm{SD}$; Patients having co-morbid systemic autoimmune condition $(n=5)$ were excluded except in two cases having retinal neurodegeneration.

\section{Dose-dependence and titer of diabetic protein-A eluate binding to Q..N-18}

Titer and potency of IgG autoantibody binding to the Q..-N-18 linear synthetic peptide was substantially increased in subsets of diabetes suffering with recurrent stroke, diabetes with co-morbid discoid lupus erythematosus and retinitis pigmentosa, diabetes having dementia, and diabetes with Parkinson's disease. Peak binding and titer was not elevated in representative older type 2 diabetes without neurodegeneration and without significant angiopathy (i.e. retinopathy and nephropathy), i.e. $<2$-fold above background absorbance at IgG concentrations tested between $1-2 \mu \mathrm{g} / \mathrm{mL}$ (Table 6).

Table 6. Potency and titer of receptor peptide autoantibodies in representative patients.

\begin{tabular}{|l|c|c|}
\hline \multicolumn{1}{|c|}{ Diagnosis } & Titer of autoantibody & Peak Binding (AU) \\
\hline $\begin{array}{l}\text { Retinitis pigmentosa \& } \\
\text { Discoid lupus erythematosus }\end{array}$ & $0.37 \mu \mathrm{g} / \mathrm{mL}$ & 0.25 \\
\hline DM, Refractory hypertension & $2 \mu \mathrm{g} / \mathrm{mL}$ & 0.17 \\
\hline DM, Dementia & $0.4 \mu \mathrm{g} / \mathrm{mL}$ & 0.14 \\
\hline DM, Parkinson's disease & $<1 \mu \mathrm{g} / \mathrm{mL}$ & 0.10 \\
\hline DM without ND & $1 \mu \mathrm{g} / \mathrm{mL}$ & 0.07 \\
\hline DM without angiopathy & $2 \mathrm{ug} / \mathrm{mL}$ & 0.06 \\
\hline
\end{tabular}

Absorbance units $=0.04$ is background level. $1 \mu \mathrm{g} / \mathrm{mL} \operatorname{IgG} \sim 6.7 \mathrm{nM}$.

ND- neurodegenerative disorder, DM- diabetes mellitus; Titer- concentration of autoantibodies causing $\sim 50 \%$ of maximal binding.

\section{Correlation of receptor peptide binding with IgG neurotoxicity (neurite retraction, $\mathrm{N} 2 \mathrm{~A}$ cell loss)}

There was a significant correlation between 5 -HT2A receptor synthetic peptide binding and acute N2A neurite retraction in the protein-A eluates from twenty-five patients tested (Fig 2) including representative patients from various pathologic subgroups (Table 7). High receptor peptide binding IgG was associated with significantly greater acute N2A neurite withdrawal (compared to low-binding IgG) at each of several different dilutions tested (Table 8).

'High- binding' IgG caused significantly greaterN2a neuron loss (after 24 hours incubation) than an identical concentration of 'low- 
Mark B. Zimering (2019) Autoantibodies in Type-2 Diabetes having Neurovascular Complications Bind to the Second Extracellular Loop of the 5-Hydroxytryptamine 2A Receptor

binding' IgG (Table 9). Taken together these data suggest that IgG autoantibody binding to the linear synthetic 5-HT2A (ECL2) receptor peptide is correlated with IgG autoantibody-induced N2A neurite retraction and accelerated N2A neuron loss.

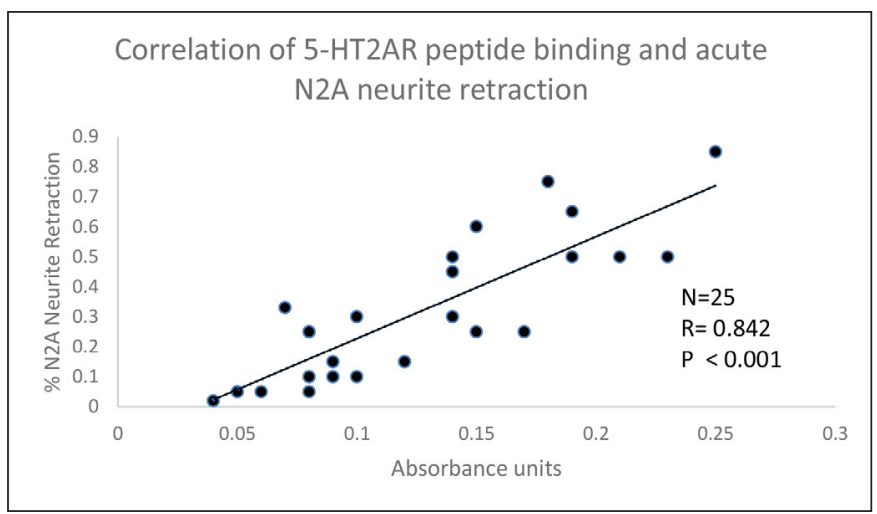

Figure 2. Correlation between 5-HT2A receptor synthetic peptide binding and acute N2A neurite retraction in the protein-A eluates from twenty-five patients with neurovascular or neuropsychiatric complications. A $1 / 40^{\text {th }}$ dilution of the protein-A eluate fraction was incubated with N2A cells and acute neurite retraction was determined as described in Materials and Methods. Results were correlated with binding to Q..N-18 in an ELISA using a $1 / 40^{\text {th }}$ dilution of the protein-A eluate of serum or plasma.

Table 7. Association between autoantibody- 5HT2ARreceptor peptide binding and autoantibody-induced acute neurite retraction by representative patient subgroup.

\begin{tabular}{|c|c|c|}
\hline Diagnosis & Binding & $\begin{array}{l}\text { Neurite } \\
\text { retraction }\end{array}$ \\
\hline \multirow[t]{3}{*}{ *Diabetes without angiopathy $(\mathrm{n}=3)$} & .04 & - \\
\hline & .06 & - \\
\hline & .08 & - \\
\hline \multirow[t]{2}{*}{ Dementia $(\mathrm{n}=2)$} & .15 & ++ \\
\hline & .14 & +++ \\
\hline \multirow[t]{4}{*}{ Schizophrenia $(\mathrm{n}=4)$} & .08 & ++ \\
\hline & .08 & ++ \\
\hline & .10 & - \\
\hline & .07 & ++ \\
\hline \multirow[t]{2}{*}{ Major depressive disorder $(\mathrm{n}=2)$} & .14 & ++ \\
\hline & .23 & +++ \\
\hline \multirow[t]{7}{*}{ Parkinsons Disease $(\mathrm{n}=7)$} & .14 & +++ \\
\hline & .19 & +++ \\
\hline & .10 & ++ \\
\hline & .15 & ++++ \\
\hline & .19 & ++++ \\
\hline & .21 & +++ \\
\hline & .09 & + \\
\hline \multirow[t]{2}{*}{ Stroke $(\mathrm{n}=2)$} & .18 & +++++ \\
\hline & .25 & +++++ \\
\hline
\end{tabular}

*Neurite retraction scale: $\%$ neurite shortening after 5 minutes'exposure to autoantibodies , i.e. $0-10 \%=(-) ; 11-24 \%(+) ; 25-33 \%(++) ; 34-50 \%(+++) ; 51-74 \%(++++) ; 75-85 \%$ $(+++++)$.

Soluble ECL2 peptide inhibits DM autoantibody-induced N2A neurite retraction

An 18-mericlinear synthetic peptide (Q..N-18) having an identical amino acid sequence to the ECL2 of the 5-HT2A receptor dose-dependently inhibited mouse N2A neuroblastoma cell neurite retraction induced by a sixty Nano molar concentration of the protein-A eluate fraction of plasma from Patient 1 type 2 diabetes suffering with refractory hypertension, retinal vein occlusion, and transient ischemic attack (TIA). The Patient 1 refractory hypertension autoantibodies alone caused $90 \%$ neurite retraction in N2a cells (Table 10). Half-maximal inhibition of autoantibody-induced acute neurite retraction occurred at a $2 \mu \mathrm{g} / \mathrm{mL}$ concentration of Q..N-18, corresponding to $\sim 1 \mu \mathrm{M}$ concentration of the peptide (Table 10).

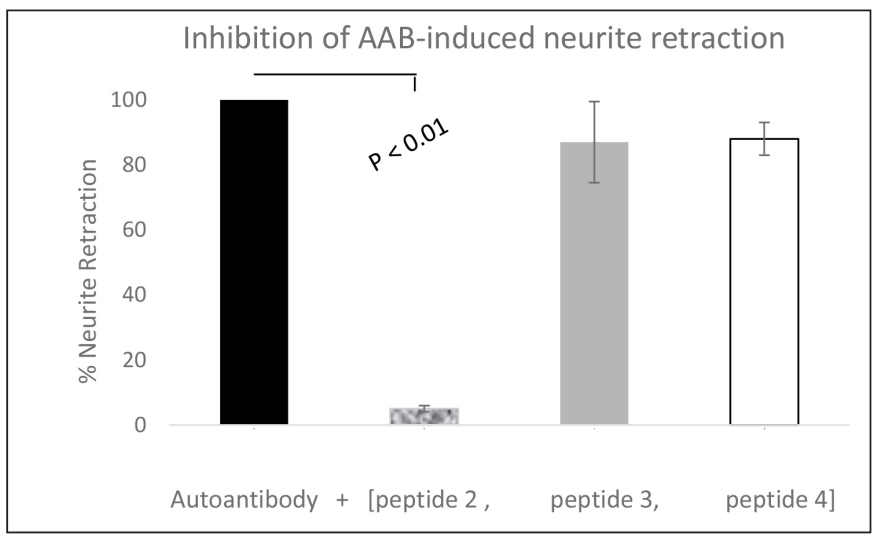

Figure 3. A $1 / 40^{\text {th }}$ dilution of the Pt 1 refractory hypertension plasma autoantibodies(AAB) was incubated with N2A neuroblastoma cells alone (solid bar) or in the presence of a 20 $\mu \mathrm{g} / \mathrm{mL}$ concentration of peptide 2 ((SCLLADDN), peptide 3 (QDDSKVF), or peptide 4 (VFKEGSC)(open bar). Results are (mean $\pm \mathrm{SD}$ ) acute neurite retraction determined as described in Materials and Methods.

Table 8. Dose-dependent, increased autoantibody-induced neurite retraction in DM having neurodegeneration or cancer vs. DM without neurodegeneration or cancer

\begin{tabular}{|l|l|l|l|l|l|}
\hline \multicolumn{2}{|c|}{ Receptor Peptide } & \multicolumn{4}{c|}{ Autoantibody Dilution } \\
\hline Diagnosis & $\begin{array}{l}\text { Binding } \\
\text { (AU + SD) }\end{array}$ & $\mathbf{1 / 4 0 ^ { \text { th } }}$ & $\mathbf{1 / 6 0 ^ { \text { th } }}$ & $\mathbf{1} / \mathbf{1 0 0}^{\text {th }}$ & $\mathbf{1 / 2 0 0}^{\text {th }}$ \\
\hline PD(1), & Stroke(2), & $\begin{array}{l}\text { High } \\
\text { binders }\end{array}$ & & & \\
\hline $\begin{array}{l}\text { Prostate cancer } \\
(1)\end{array}$ & $(0.21+.03)$ & $72+13 \% \wedge$ & $\begin{array}{l}44+ \\
6 \% *\end{array}$ & $33 \%$ & $25 \%$ \\
\hline $\begin{array}{l}\text { Schizophrenia } \\
(1),\end{array}$ & Low binders & $20+12 \%$ & $\begin{array}{l}13 \\
+10 \%\end{array}$ & NR & NR \\
\hline $\begin{array}{l}\text { uncompl DM } \\
(2)\end{array}$ & $(0.06+.01)$ & & & & \\
\hline
\end{tabular}

Results are mean + SD \% neurite retraction after 5 minutes exposure to indicated dilution of autoantibodies; NR- nodetectabeneurite retraction. ${ }^{\wedge} \mathrm{P}<0.002 ; * \mathrm{P}<0.02$ - compared to neurite retraction at same autoantibody dilution in low peptide binding IgG autoantibodies subgroup; AU- absorbance units, SD-standard deviation.Uncomplicated diabetes mellitus- without microvascular complications.

Table 9. Association between autoantibody- receptor peptide binding and autoantibodyinduced accelerated N2A neuron loss.

\begin{tabular}{|l|l|l|l|}
\hline & Low-binding (N=7) & High-binding (N=5) & P-value \\
\hline Absorbance (AU) & $0.08+0.019$ & $0.22+0.04$ & $<0.001$ \\
\hline \% N2A cell survival & $91.7+5.9 \%$ & $66.4+9.1 \%$ & $<0.001$ \\
\hline
\end{tabular}

Results are mean +/- SD. Neuron survival was determined after 24 hours incubation as described in Materials and Methods. 
Table 10. Dose-dependent inhibition of autoantibody-induced acute N2A neurite withdrawal by co-incubation with 18-meric Q..N linear synthetic peptide Autoantibody (one sixtieth dilution) $+(\mathrm{Q} \ldots \mathrm{N}-18)$ at

\begin{tabular}{|c|c|c|l|}
\hline Diagnosis & $(\mathbf{0} \boldsymbol{\mu g} / \mathbf{m L})$ & $(\mathbf{3} \boldsymbol{\mu g} / \mathbf{m L})$ & $(\mathbf{5} \boldsymbol{\mu g} / \mathbf{m L})$ \\
\hline DM, refractory hypertension (N=1) & $90+5 \%$ & $25+7 \%$ & $0+0 \%$ \\
\hline
\end{tabular}

The indicated concentration of theQ..N-18 linear synthetic 5HT2A receptor peptide was co-incubated with a $100 \mathrm{nM}$ concentration of the Patient 1 , diabetes (DM) refractory hypertension autoantibodies. Acute N2A neurite retraction was assessed after 5 minutes as described in Materials and Methods.

\section{Epitope mapping of region within 5-HT2AR, ECL2 peptide targeted by autoantibodies}

We next performed epitope 'mapping' of the region within the second extracellular loop region of 5-HT2A receptor targeted by the type 2 diabetes and neurodegenerative pathologies' autoantibodies. Each of three short overlapping ECL2-region peptides was preincubated alone (for 5 minutes) with N2A cells prior to the addition of Patient 1, refraction hypertension IgG autoantibodies. Peptide 3or4 (at $20 \mu \mathrm{g} / \mathrm{mL}$ concentration) had no significant effect on Patient $1 \mathrm{IgG}$ autoantibody-induced neurite withdrawal. Peptide $2(20 \mu \mathrm{g} / \mathrm{mL})$ dosedependently nearly completely prevented acute neurite retraction induced by the Patient 1, refractory hypertension $\operatorname{IgG}$ autoantibodies (Table 11).

Table 11. Identification of a short linear peptide that blocks autoantibody (IgG)-induced neurite retraction.

\begin{tabular}{|c|c|}
\hline Treatment & Mean acute N2A neurite retraction (\%) \\
\hline DM, refractory hypertension IgG* & $100+0 \%$ \\
\hline Pt1 IgG + Peptide 3 (QDDSKVF) & $87+19 \%$ \\
\hline Pt1 IgG + Peptide 2(SCLLADDN) & $5+5 \% *$ \\
\hline Pt1 IgG + Peptide 4(VFKEGSC) & $88+13 \%$ \\
\hline
\end{tabular}

*A one-fortieth dilution of the Pt 1 diabetic refractory hypertension IgG autoantibodies was incubated in the presence or absence of a $20 \mu \mathrm{g} / \mathrm{mL}$ concentration of three different short linear synthetic peptides comprising portions of the second extracellular loop of 5 -HT2A receptor. Results are mean $+/$ SD acute N2A neurite retraction after 5 minutes. Peptide $2(20 \mu \mathrm{g} / \mathrm{mL})$ was associated with $95 \%$ protection against the diabetic stroke pathologies IgG-induced neurite retraction. Peptide 3 or Peptide 4 at identical $(20 \mu \mathrm{g} /$ $\mathrm{mL}$ ) concentration had no significant protective effect on IgG autoantibody-induced N2A neurite retraction.

\section{Sub region-specific 5-HT2AR, ECL2 peptide protects against autoantibody neurotoxicity}

A brief pre incubation with Peptide $2(20 \mu \mathrm{g} / \mathrm{mL})$ nearly completely prevented (99\%) IgG-induced acute neurite withdrawal induced by a $50-100 \mathrm{nM}$ concentration of pathologies' IgG autoantibodies in ten of ten patients tested (Table 12).

Table 12. Neutralization of diabetic autoantibody-induced N2A acute neurite retraction by a linear synthetic short peptide contained within the 5-HT2A receptor ECL2, i.e. Peptide 2 .

Acute $N 2 A$ neurite retraction in $\operatorname{Ig} G$ autoantibodies

\begin{tabular}{|l|l|l|l|}
\hline $\begin{array}{l}\text { Pathologies } \\
\text { Autoantibodies (N=10) }\end{array}$ & (without Peptide 2) & (with Peptide 2) & $\boldsymbol{P}$-value \\
\hline $\begin{array}{l}\text { Dementia (2), } \\
\text { PD(3), Stroke(2), } \\
\text { Schizophrenia(3) }\end{array}$ & $33 \%+8 \%$ & $0.25 \%+0.75 \%$ & $<0.001$ \\
\hline
\end{tabular}

ECL2- second extracellular loop region of 5-HT2A receptor; PD-Parkinson's disease
Co-incubation with peptide $2(20 \mu \mathrm{g} / \mathrm{mL})$ completely protected N2A cells from accelerated neuron loss caused by a1 $/ 100^{\text {th }}$ dilution of Patient 1, refractory hypertension IgG autoantibodies (Table 13). After 16 hours' incubation (at 37 degrees C) with Patient 1 or the IgG autoantibodies from four different patients suffering with stroke, Parkinson's disease, dementia or major depressive disorder, peptide 2 $(20 \mu \mathrm{g} / \mathrm{mL})$ afforded substantial neuro protection against accelerated neuron loss (Table 14).

Table 13. Neutralization of diabetic IgG-induced accelerated N2A cell loss by Peptide 2, a short linear synthetic peptide corresponding to a portion of 5-HT2AR second extracellular loop region.

\begin{tabular}{|c|c|c|c|}
\hline Pathology & $\begin{array}{c}\text { Pt 1 IgG } \\
\text { alone }\end{array}$ & $\begin{array}{c}\text { Pt 1 IgG + } \\
\text { Peptide 2 }\end{array}$ & P-value \\
\hline DM refractory HTN $(\mathrm{n}=1)$ & $57+3 \%$ & $100+4 \%$ & 0.005 \\
\hline
\end{tabular}

A $1 / 100^{\text {th }}$ dilution of the diabetes (DM) refractory hypertension (HTN), plasma $\operatorname{IgG}$ autoantibodies was incubated for 16 hours in the presence or absence of a $20 \mu \mathrm{g} / \mathrm{mL}$ concentration of the linear synthetic peptide, Peptide 2. Results are mean $+/$ - (SD) percent of basal N2A neuroblastoma cell survival.

Table 14. Neutralization of diabetic (IgG) autoantibody-induced accelerated N2A cell loss by Peptide 2, a short linear synthetic peptide corresponding to a portion of 5-HT2AR, ECL2.

\begin{tabular}{|l|l|l|l|}
\hline \multicolumn{1}{|c|}{ Diagnosis(N=5) } & IgG alone & IgG + Peptide 2 & P-value \\
\hline $\begin{array}{l}\text { Stroke(2), PD(1), } \\
\text { Dementia(1), MDD(1) }\end{array}$ & $64+21 \%$ & $94+11 \%$ & 0.03 \\
\hline
\end{tabular}

Results are mean + SD N2A cell survival after 16 hours incubation of the indicated diabetic pathologies IgG autoantibodies in the presence or absence of $20 \mathrm{ug} / \mathrm{mL}$ Peptide 2. PD-Parkinson'disease, MDD-major depressive disorder.

\section{In silico test of 5-HT2A receptor peptide's binding affinity for major histocompatibility complex class II (MHC-II) molecules}

We used the Immune Epitope Database (IEDB) and an improved prediction tool [9] to test whether a portion of the Peptide 2 amino acid sequence corresponds to an 'immune epitope,i.e. a sequence which displays significant binding affinity to one or more alleles comprising MHC class II,HLA-DR, HLA-DQ, or HLA-DP molecules. The 15-meric linear peptide sequence(s) SKVFKEGSCLLADDN which includes Peptide 2 (underlined) was tested for binding to MHC class II molecules. There was no significant high affinity binding to alleles comprising the HLA-DR or HLA-DP loci. The core amino acid sequence, KEGSCLLAD displayed significant binding affinity (i.e. $\mathrm{K}_{\mathrm{a}} 217 \mathrm{nM}$ ), to one specific HLA-DQ allele, DQA10102-DQB10602.

\section{Discussion}

Type 2 diabetes is not an autoimmune disease. Yet the present data suggest humoral immune responses to the 5-hydroxytryptamine (serotonin) 2A receptor in subsets of older adult obese type 2 diabetes suffering with diabetic macular edema, and proteinuric nephropathy. Aging, diffuse vascular injury and visceral obesity may each contribute to humoral immunity to the 5HT2A receptor. A role for chronic inflammation and hemodynamic factors is suggested by the observation of significantly increased ECL2 receptor peptide binding in subsets of patients with nephropathy and chronic kidney disease. The high prevalence of increased 5-HT2A receptor peptide binding in 
autoantibodies from patients suffering with Parkinson's disease (14/17), major depression (9/12), stroke (6/7), and dementia (4/7), is unlikely to represent 'non-specific binding' since autoantibody binding (in the ELISA) was significantly associated with both autoantibody-induced neurite retraction and accelerated N2A cell loss. The correlation between receptor peptide binding and neurotoxicity demonstrated here suggests that neurovascular IgG autoantibody binding to the5HT2AR second extracellular loop causes receptor activation which as previously reported was positively coupled to $\mathrm{PLC} / \mathrm{IP} 3 / \mathrm{Ca} 2+$ and RhoA/ROCK signaling pathway activation $[2,3]$.

The second extracellular loop region loop lies in close proximity to the Orthosteric Binding Pocket (OBP) [4] and has a role in preventing normal constitutive receptor activation in biogenic and trace amine G-Protein Coupled Receptors (GPCRs) [10]. Neurovascular pathologies' autoantibodies appeared to target a conserved sub region in ECL2 [10] important in promoting sustained activation of the 5HT2B and 5HT2A receptors by the hallucinogenic drug Lysergic Acid Diethylamine (LSD) [4]. In a recent study by Wacker et. al. [4], the atomic structure of LSD complexes to the $5-\mathrm{HT} 2 \mathrm{~B}$ and $-2 \mathrm{~A}$ receptors was reported. Lysergic acid diethylamide-known to have long-lasting effects in humans-exhibited unusually long residence times at the 5 -HT-2B and -2A receptors, i.e. off-reaction times of $\sim 45$ minutes and $\sim 220$ minutes, respectively [4]. Wacker and co-authors reported that amino acid residues 207-214 in 5-HT2BR form a 'lid' which blocks the opening to the orthosteric binding pocket likely accounting for LSD's prolonged off-reaction time at the receptor [4]. Of interest, seven of the eight amino acid residues comprising the inhibitory Peptide 2 sequence SCLLADDN (underlined here) form the corresponding 'lid' region in the 5-HT2A receptor, including the conserved amino acid residue, leucine 229 (bolded), which is present in all three 5-HT2 $(-A,-B$, and $-C)$ receptor isoforms [10] One of the striking features of the neurovascular pathologies' autoantibodies effect in N2A cells was its long duration of action, i.e. neurite retraction was essentially irreversible after 45 minutes' or longer observation times. Serotonin or the 5HT2A receptor agonist DOI promoted neurite retraction which peaked after (3-5 minutes) and was reversible at longer times [3]. Taken together with the structural data on the LSD bound 5-HT2R [4], these data suggest that neurovascular autoantibodies may binding at a critical region in the second extracellular loop involved in stabilizing a 'persistently-active' conformation of the 5HT2A receptor.

Systemic autoimmunity is associated with a wide variety of autoantibodies capable of targeting diverse auto antigens. In the present study, highest binding to the 5-HTR2AR linear synthetic peptide occurred in two patients with a systemic autoimmune condition, i.e. discoid (cutaneous) lupus erythematosus (Pt 2) or HLAB27- positive ankylosing spondylitis. Heparan Sulfate Proteoglycans (HSPG) is among a small group of overlapping auto antigens reported in both systemic lupus erythematosus [11] and ankylosing spondylitis [12]. Heparan sulfate proteoglycans are strongly anionic at physiologic $\mathrm{pH}$. They are abundantly expressed in extracellular matrix and on vascular and neuronal surfaces where they have role(s) in the maintenance of tissue barriers and serve as low-affinity co-receptors for cationic 'heparin-binding' growth factors, e.g. basic fibroblast growth factor (FGF-2) [13]. Neurotoxic and endothelial cell inhibitory autoantibodies previously reported in subsets of diabetes complicated by painful neuropathy, nephropathy, macular edema or primary open angle glaucoma [14] displayed increased affinity for heparan sulfate proteoglycan [14] or a heparin Sepharose column [15]. Glomerular HSPG are elaborated in diabetic nephropathy [16], and may be a target of heightened humoral autoimmunity especially under conditions of chronic inflammation which prevail in chronic kidney disease.

The putative dominant epitope targeted by 5 -HT2A receptor activating autoantibodies in the present study contains a di-aspartic acid motif (SCLLADDN) not present in the 5-HT2B receptor [10]. It is interesting to speculate that the negative charge(s) associated with having di-aspartic acid residues in a solvent-exposed region of the receptor may provide a basis for strong electrostatic interaction with circulating IgG pathologies autoantibodies. In a prior report, neurotoxicity in diabetic dementia and PD dementia IgG autoantibodies was enhanced eight-fold following chromatography of plasma on a dextran sulfate affinity chromatography column [2]. Dextran sulfate (Liposorber) apheresis issued to lower excessive concentrations of cationic lipoprotein particles (very low density, and low-density lipoproteins) in the circulation in patients with familial hypercholesterolemia. It is possible that neurovascular pathologies autoantibodies co-purified with cationic lipoprotein particles based on having similar cationic surface charge characteristics which may contribute to an electrostatic interaction with anionic sulfate groups.

Prostate expresses high level of HSPG [17] which acts as a coreceptor for several different fibroblast growth factors having key role(s) in stromal proliferation underlying prostate cancer progression [18]. Among nine patients in the present study who had co-morbid prostate $(n=8)$ or bladder $(n=1)$ cancer, the mean level of 5-HT2AR autoantibody peptide binding was $0.14 \mathrm{AU}$, i.e. 3.5 -fold higher than background (0.04 AU). Eight of the nine prostate or bladder cancer patients suffered with a neurodegenerative $(n=5 P D, n=1$ dementia) or neuropsychiatric disorder ( $\mathrm{N}=1 \mathrm{MDD}, \mathrm{N}=1$ schizophrenia). In most of these patients, the cancer diagnosis and treatment was established prior to the onset of neurologic or neuropsychiatric disease manifestations perhaps consistent with a paraneoplastic mechanism for humoral autoimmunity to 5 - $\mathrm{HT} 2 \mathrm{~A}$ receptor activating autoantibodies. In a prior report, prostate cancer autoantibodies in patients suffering with fatigue/depression were highly neurotoxic and evoked large increases inward cationic current in (whole-cell patch clamped) rat hippocampal pyramidal neurons associated with long-lasting desensitization of excitatory synaptic inputs [14]. Taken together with the present data, these findings suggest that 5 -HT2A receptor found on cortical pyramidal neurons or in other brain regions may mediate glutamatergic excitatory post-synaptic actions in response to 5-HT2A receptor- activating autoantibodies [19].

A short linear synthetic peptide comprising a region of the second extracellular loop of the 5HT2A receptor, i.e. peptide 2, largely prevented autoantibody- induced neurotoxicity perhaps by competing for binding to the region of the 5-HT2R targeted by a majority of the autoantibodies tested. The peptide antagonist (SCLLADDN) retained its neuro protective effect (against autoantibody-induced N2A cell loss) even after 16 hours' incubation time (at 37 degrees $\mathrm{C}$ ) in the presence of $10 \%$ fetal calf serum. A hallmark property of an auto 
antigen's immune dominant epitope is its ability to survive complete intracellular proteolytic processing [20]. Our in silico analysis suggests that Peptide 2 having the sequence SCLLADDN may comprise an immune dominant peptide which is specifically 'recognized' by the major histocompatibility complex class II molecular system through high affinity binding interaction with the specific HLA-DQ allele, DQA10102-DQB10602. Of interest, DQA10102-DQB10602 was previously reported to have conferred markedly increased susceptibility to narcolepsy-cataplexy in certain populations [21]. Narcolepsy is a putative neurodegenerative process affecting hypocretin neurons located in the lateral hypothalamus [22]. Narcolepsy incidence rates in young adults were reported to have peaked following the 2009 H1N1 influenza pandemic [23] and related H1N1 vaccination regimes [24] suggesting molecular mimicry with certain strains of influenza viruses as one possible mechanism for T-cell driven auto immunity in the unknown etiology of a subset of 'autoimmune' narcolepsy-cataplexy in HLA-DQ susceptible persons [25].

Highest level of 5-HT2AR, ECL2 autoantibody binding, i.e. 6.25 times above background, occurred in an older man (Patient 2) having discoid lupus erythematosus, and near blindness secondary to central retina artery occlusion and retinitis pigmentosa. It is of interest that 5-HT2AR immune reactivity was reported on the terminals of photoreceptors and bipolar cells in rabbit retina [26]. In addition, 5-HT2AR antagonists afforded protection against light-induced photoreceptor degeneration in certain susceptible genetic strains of mice [27]. Plasma autoantibodies in Patient 3, an 81 year-old-man who suffered with autoimmune thyroid disease and juvenile-onset retinitis pigmentosa (i.e. Stargardt disease), displayed significantly increased binding (2.5-fold background) in the ELISA. Taken together, these data suggest systemic autoimmunity in which humoral autoantibodies are directed against many different autoantigen epitopes might provide a humoral-mediated mechanism contributing to retinal degeneration occurring in genetically-susceptible patients. The 5-HT2AR ECL2 peptide-based ELISA might be useful in screening family members of affected patients suffering with genetic forms of retinal degeneration. More in vivo study of the antagonist peptide is needed to determine whether it might be neuro protective in an animal model of retinal degeneration.

The source(s) of 5-HT2AR autoantigen in angiopathic type 2 diabetes is not known. Obese diabetes is associated with increased inflammation and the latter is associated with higher risk of thrombosis. Since 5-HT2AR is expressed on platelets, it is possible that diabetic microangiopathy predisposes to micro thrombi formation at sites of inflammation which may cause 5HT2A receptor to be taken up and processed by macrophages and/or other professional antigen presenting cells. Monocytes have been reported to adhere to platelets at sites of inflammation via specific interactions not observed between platelets and other subtypes of white blood cells [28].

Our study was cross-sectional and included mostly older men. More longitudinal study in diverse (unselected) populations is needed to estimate the actual prevalence of 5-HT2AR- activating autoantibodies and whether a dose-response relationship may exist between the autoantibodies and one or more kind of neurodegenerative disorder.
In summary, the present data provide the first evidence that subsets of major depressive disorder, Parkinson's disease, dementia, small vessel stroke (e.g. retinal artery occlusion), refractory hypertension, and proteinuric nephropathy (in both diabetes and obese non-diabetic older persons) harbored IgG autoantibodies which bound to a region of the second extracellular loop of the human 5HT2A receptor [4] previously implicated in causing long-lasting receptor activation.

\section{References}

1. Hu G (2007) Type 2 Diabetes and the Risk of Parkinson's Disease. Diabetes Care 30: $842-847$.

2. Zimering MB (2018) Circulating Neurotoxic 5-HT2A Receptor Agonist Autoantibodies in Adult Type 2 Diabetes with Parkinson's Disease. J Endocrinol Diabetes 5 .

3. Zimering MB (2017) Diabetes Autoantibodies Mediate Neural- and Endothelial Cell- Inhibitory Effects Via 5-Hydroxytryptamine- 2 Receptor Coupled to Phospholipase C/Inositol Triphosphate/Ca2+ Pathway. J Endocrinol Diabetes 4.

4. Wacker D, Wang S, McCorvy JD, Betz RM, Venkatakrishnan AJ, et al. (2017) Crystal Structure of an LSD-Bound Human SerotoninReceptor. Cell 168: 377-389.

5. Holthoff HP, Zeibig S, Jahns-Boivin V, Bauer J, Lohse MJ, et al. (2012) Detection of anti- $\beta 1$-AR autoantibodies in heart failure by a cell-based competition ELISA. Circ Res111: 675-684

6. Dechend R, Gratze P, Wallukat G, Shagdarsuren E, Plehm R, et al.( 2005) Agonistic autoantibodies to the AT1 receptor in a transgenic rat model of preeclampsia. Hypertension 45: 742-746.

7. Xu T, Pandey SC (2000) Cellular localization of serotonin (2A) (5HT (2A)) receptors in the rat brain. Brain Res Bull 51: 499-505.

8. Alsip NL, Harris PD, Durrani GE (1991) Multiple Serotonin Receptors on Large Arterioles in Striated Muscle. J Vasc Res 28: 537-541.

9. Jensen KK, Andreatta M, Marcatili P, Buus S, Greenbaum JA, et al. (2018) Improved methods for predicting peptide binding affinity to MHC class II molecules Immunology 154: 394-406.

10. Michino M, Beuming T, Donthamsetti P, et al. (2015) What Can Crystal Structures of Aminergic Receptors Tell Us about Designing Subtype-Selective Ligands? Pharmacol Rev 67: 198-213

11. Shibata S, Sasaki T, Harpel P, Fillit H (1994) Autoantibodies to vascular heparan sulfate proteoglycan in systemic lupus erythematosus react with endothelial cells and inhibit the formation of thrombin-antithrombin III complexes. Clin Immunol Immunopathol 70: 114-123.

12. Wright C, Sibani S, Trudgian D, Fischer R, Kessler B, et al. (2012) Detection of multiple autoantibodies in patients with ankylosing spondylitis using nucleic acid programmable protein arrays. Mol Cell Proteomics 11: 00384.

13. Bernfield M, Sanderson RD (1990) a developmentally regulated cell surface proteoglycan that binds extracellular matrix and growth factors. Philos Trans $R$ Soc Lond B Biol Sci 327: 171-186

14. Zimering MB, Alder J, Pan Z, Donnelly RJ (2011) Anti-endothelial and antineuronal effects from auto-antibodies in subsets of adult diabetes having a cluster of microvascular complications. Diabetes Res Clin Pract 93: 95-105.

15. Zimering MB, Anderson RJ, Moritz T, Ge L (2009) Investigators for the VADT Low plasma basic fibroblast growth factor is associated with laser photocoagulation treatment in adult type 2 diabetes mellitus from the Veterans Affairs Diabetes Trial. Metabolism 58: 393-400

16. Makino H, Ikeda S, Haramoto T, Ota Z (1992) Heparan sulfate proteoglycans are lost in patients with diabetic nephropathy. Nephron 61: 415-421.

17. Kosir MA, Quinn CC (1995) Sorting of heparan sulfate proteoglycan into matrix compartments of prostate adenocarcinoma cells. J Surg Res 58: 46-52.

18. Wu X, Kan M, Wang F, Jin C, Yu C, et al. (2001) A rare premalignant prostate tumor epithelial cell syndecan-1 forms a fibroblast growth factor-binding complex with progression-promoting ectopic fibroblast growth factor receptor 1.Cancer Res 61: 5295-5302.

19. Aghajanian GK, Marek GJ (1997) Serotonin induces excitatory postsynaptic potentials in apical dendrites of neocortical pyramidal cells. Neuropharmacology 36: 589-599.

20. Kim A, Sadegh-Nasseri S (2015) Determinants of immunodominance for CD4 T cells. CurrOpin Immunol 34: 9-15.

21. Mignot E, Lin L, Rogers W, Honda Y, Qiu X, Lin (2001) Complex HLA-DR and -DQ interactions confer risk of narcolepsy-cataplexy in three ethnic groups. $\mathrm{Am} J$ Hum Genet 68: 686-699.

22. Nishino S, Ripley B, Overeem S, Lammers GJ, Mignot E (2000) Hypocretin (orexin) deficiency in human narcolepsy. Lancet 355: 39-40. 
Mark B. Zimering (2019) Autoantibodies in Type-2 Diabetes having Neurovascular Complications Bind to the Second Extracellular Loop of the 5-Hydroxytryptamine 2A Receptor

23. Nohynek H, Jokinen J, Partinen M, Vaarala O, Kirjavainen T, et al. (2012) S03 adjuvanted AH1N1 vaccine associated with an abrupt increase in the incidence of childhood narcolepsy in Finland. PLoS One 7: 33536.

24. Han F, Lin L, Warby SC, Faraco J, Li J, et al (2011) Narcolepsy onset is seasonal and increased following the 2009 H1N1 pandemic in China. Ann Neurol 70: 410-417.

25. Black JIII, Avula R, Walker D, Silber M, KrahnL, et al. (2005) HLA DQB1*0602 positive narcoleptic subjects with cataplexy have CSF IgG reactive to rat hypothalamic protein extract. Sleep 28: 1191-1192
26. Pootanakit K, Prior KJ, Hunter DD, Brunken WJ (1999) 5-HT2a receptors in the rabbit retina: potential presynaptic modulators. Vis Neurosci 16: 221-230.

27. Chen Y, Okano K, Maeda T, Chauhan V, Golczak M, et al.(2012) Mechanism of alltrans-retinal toxicity with implications for stargardt disease and age-related macular degeneration. J Biol Chem 287: 5059-5069.

28. Passacquale G, Vamadevan P, Pereira L, Hamid C, Corrigall V, et al (2011) Monocyte-platelet interaction induces a pro-inflammatory phenotype in circulating monocytes. PLoS One 6: 25595.

\section{Citation:}

Mark B. Zimering (2019) Autoantibodies in Type-2 Diabetes having Neurovascular Complications Bind to the Second Extracellular Loop of the 5-Hydroxytryptamine 2A Receptor. Endocrinol Diabetes Metab J Volume 3(4): 1-8. 